\title{
QUESTÃO AMBIENTAL E DESENVOLVIMENTO: CRISES E PERSPECTIVAS
}

\section{Munir Jorge Felício ${ }^{1}$}

\section{Aglaís Mancini dos Santos ${ }^{2}$}

\section{Lúcia Andreia dos Santos Martins ${ }^{3}$}

RESUMO: Compreender de que forma a questão ambiental pode ser uma das consequências do modelo de desenvolvimento impulsionado pela racionalidade econômica capitalista tem provocado debates dentro e fora da academia. Esse texto faz parte desses debates. Trata-se de refletir sobre essa racionalidade econômica que vem se impondo pela força de sua eficiência produtiva, pela constante tecnificação dos meios de produção configurando num processo de acumulação do capital de tendência essencialmente hegemônica. Essa racionalidade tem impulsionado o pensamento fetichizado por defender o modelo de desenvolvimento capitalista como totalidade em que não há possibilidade de outro modelo. Conhecer as raízes do desenvolvimento desse modo de produção e estudar os impactos ambientais causados por ele exige rupturas epistemológicas e mudanças paradigmáticas. Este texto, como parte das discussões da iniciação científica, se apoia nas análises de pesquisadores como Leff (2000); Sen (2008), Sóglio (2009); Mazoyer e Roudart (1998); Diamond (2012); Huberman (1979) Catani (1988) e Arrighi (2009), entre outros, retirando dessas contribuições significações, justificativas e interpretações com as quais compreender o como e o porquê a questão ambiental pode ser um dos resultados da implantação e do avanço do modelo de desenvolvimento guiado pelas leis da acumulação

\footnotetext{
${ }^{1}$ Doutor, docente do Mestrado em Meio Ambiente e Desenvolvimento Regional - MMADRE UNOESTEMADRE, munir@unoeste.br

${ }^{2}$ Acadêmica de Administração, UNOESTE, aglais.m.santos@hotmail.com

${ }^{3}$ Acadêmica de Administração, UNOESTE, lupercia_andreia@hotmail.com
} 
do capital. A medida em essas discussões foi avançando serviram para ampliar a compreensão do liame causal entre a questão ambiental e o desenvolvimento por intermédio de informações e dados coletados "in loco" da realidade num bairro populoso de Presidente Prudente (SP).

Palavras chave: Questão ambiental. Desenvolvimento. Capitalismo. Vida urbana.

\section{Introdução}

A questão ambiental, como questão política, abrange um conjunto de danificações ambientais, algumas irreversíveis, em consequências das ações antrópicas colocando o futuro das gerações em estado de alerta. Trata-se da destruição ou perda dos recursos naturais, do efeito estufa, do aquecimento global, da desertificação, do crescimento demográfico acelerado e desorganizado, da chuva ácida, entre outras. Para se ter uma idéia da enorme gravidade ecológica desses impactos basta constatar que mais da metade da área original das florestas do mundo foi convertida para outros usos. Desmatamento que compromete os principais serviços do ecossistema como a proteção das bacias hidrográficas, a proteção do solo contra a erosão o que interfere, significativamente, no ciclo das águas, resultando em grandes perdas de biodiversidade.

Esses aniquilamentos afetam a essência da natureza por ser ela a responsável pelo desenvolvimento de espécies selvagens, verdadeiros fornecedores de serviços gratuítos aos seres humanos que podem ser muito dispendiosos, e em muitos casos impossíveis de serem produzidos, sem o devido habitat natural. São funções indispensáveis como as que exercem as minhocas na regeneração do solo e na manutenção de sua textura, a proliferação das bactérias do solo que fixam o nitrogênio, nutriente essencial para as plantações, 0 trabalho profícuo com as polinizações executadas pelas abelhas e outros insetos.

Desde a década de 1970 as conferências mundiais chamam a atenção para a insustentabilidade do modelo de desenvolvimento em vigor no globo. São questões políticas tanto a questão ambiental quanto o modelo de desenvolvimento por isso as discussões sobre ambas têm, necessariamente, caráter político em que pese seus aspectos econômicos. Discutir essa complexidade está no horizonte dessa pesquisa. Ela visa compreender de que forma a questão ambiental pode ser um dos produtos do modelo 
de desenvolvimento. Até que ponto o esse modelo de desenvolvimento está na origem da questão ambiental?

Questionamentos como esse poderão auxiliar no debate conceitual sobre modelo de desenvolvimento e questão ambiental e fazer emergir novas compreensões e concepções problematizando os paradigmas que dão sustentabilidade teórica, política e econômica. São reflexões como essas que auxiliarão na tarefa formativa do futuro profissional da administração por Ihe proporcionar discutir suas futuras atuações dentro de uma organização empresarial.

É importante apresentar algumas reflexões a respeito da problemática ambiental a partir dos alertas sobre os limites do crescimento econômico sinalizados nas conferências mundiais desde Estocolmo em 1972. O conceito de desenvolvimento sustentável emergiu em 1987 com a Comissão Mundial sobre o Meio Ambiente e Desenvolvimento quando tratou do "Nosso Futuro Comum". Há vinte anos emergiram as recomendações de cortes de emissões de gases de efeito estufa com a conferência RioEco 92. Os créditos de carbono foram resultados das discussões do encontro de Haia, na Holanda em 2000. A mercantilização da vida foi um dos temas debatidos na Conferência Mundial Rio+20 em junho de 2012. Algumas análises sobre a problemática ambiental serão reunidas pela importância de suas contribuições como, por exemplo, Leff (2000); Sen (2008), Sóglio (2009), entre outros, serão vistos a seguir.

\section{A crise do conhecimento e a questão ambiental}

A crise do conhecimento e a crise de civilização que se instalaram no último terço do século $X X$ e que se desenvolveram no início do terceiro milênio avançaram por causa do "fracionamento do conhecimento e pela degradação do ambiente, marcados pelo logocentrismo da ciência moderna e pelo transbordamento da economização do mundo guiado pela racionalidade tecnológica e pelo livre mercado" (LEFF, 2000, p. 19). De maneira que a realidade de opulência sem precedentes, segundo Sen (2008), propicia às pessoas hoje viverem "em média muito mais tempo do que no passado, [...], entretanto, vivemos igualmente em um mundo de privação, destituição e opressões extraordinárias" (SEN, 2008, p. 9). 
$\mathrm{Na}$ grande aldeia global as diferentes regiões estão cada vez mais estreitamente unidas no campo das comunicações, do comércio e numa gigantesca permuta de alternativas difícil de imaginar um ou dois séculos atrás. A industrialização da agricultura promoveu ganhos de produtividade majorando a superfície que salta de 1 para mais de 200 hectares de área cultivada por um trabalhador como explicaram Mazoyer e Roudart (1998). Contudo, a sobrevivência humana está em risco no longo prazo. E esse ecocídio como suicídio coletivo faz as decisões ganharem caráter de imprescindibilidade dada a necessidade de alterar os rumos e garantir o futuro das gerações, "ainda que muitos dos problemas ambientais que hoje presenciamos, ou que sabemos irão ocorrer em breve, sejam irreversíveis no curto prazo" (SÓGLIO, 2009, p. 311).

Diamond (2012) procurou explicar as razões e os motivos das sociedades escolherem o fracasso ou o sucesso ao analisar os relacionamentos dessas com seu clima, geografia, recursos e parceiros. Com riqueza de detalhes demonstra que algumas sociedades do passado falharam e outras foram bem-sucedidas e salienta, com isso, a importância de não se esquecer do passado por ele oferecer "um rico banco de dados com o qual podemos aprender, e continuar a ser bem-sucedidos" (DIAMOND, 2012, p.12).

Ao refletir sobre o fracasso da ilha de Páscoa detecta que, uma população composta de duas mil pessoas alimentando-se de batata-doce, inhame, taro, bananas, cana-de-açúcar e galinhas construíram mais de 397 estátuas de pedra. Algumas com mais de 20 metros de altura e pesando de 10 a 270 toneladas. Todas esculpidas manualmente e erigidas sem o uso de guindastes, rodas, máquinas, instrumentos de metal e sem nenhum animal de tração e nenhum meio além da força humana. A operação era executada com "cordas grossas feitas de casca fibrosa de árvores com as quais 50 a 500 pessoas podiam arrastar estátuas pesando de 10 a 90 toneladas" (DIAMOND, 2012, p. 132). Por não cuidar das suas florestas os habitantes da ilha de Páscoa apressaram o seu crepúsculo.

Desmatamento e erosão também fazem parte do colapso da antiga civilização maia da península de Yucatán, no México. "Os maias nos advertem que os colapsos também podem cair sobre sociedades avançadas e criativas" ressalta Diamond (2012, p. 199). "Como povos antigos conseguiram manter sociedades urbanas em áreas onde apenas alguns fazendeiros conseguem sobreviver atualmente?" questiona Diamond 
(2012, p. 195). Trata-se de uma civilização profundamente culta, educada e peculiar que souberam preservar sua maior riqueza: a água doce. Com uma agricultura itinerante abasteciam-se de milho, responsável por $70 \%$ de sua dieta e obtinham proteínas por meio da caça e pesca. As análises de Diamond (2012, p. 216-217) demonstram os cinco elementos como principais causadores do colapso maia: a) crescimento populacional superando os recursos disponíveis; b) os efeitos do desmatamento e da erosão das encostas; c) acirramento dos conflitos políticos internos; d) seca e e) as autoridades maias não souberam reconhecer e resolver seus problemas aparentemente óbvios.

Às essas análises que refletiram sobre as ações antrópicas impactando o meio ambiente juntar-se-ão outras que tratam da expansão econômica por ela ter, na sua essência, um modelo de desenvolvimento, como estão explanadas nas contribuições de Huberman (1979) Catani (1988); Arrighi (2009), entre outros. Huberman (1979) tenta explicar, em termos de desenvolvimento das instituições econômicas, por que certas doutrinas surgiram em determinado momento, como se originaram na própria estrutura da vida social, e como se desenvolveram, modificaram e foram ultrapassadas, ao mudarem os padrões daquela estrutura.

Tratando dos bens mundanos do ser humano Huberman reunir em duas partes o que ele denominou de Historia da Riqueza do Homem. Na primeira parte ele procura compreender como se deram as transformações da sociedade feudal para a sociedade capitalista. "A sociedade feudal consistia dessas três classes - sacerdotes, guerreiros e trabalhadores - sendo que o homem que trabalhava produzia para ambas as outras classes, eclesiástica e militar" (HUBERMAN, 1979, p. 11). Na segunda parte ele demonstra como surgiu o modo de produção capitalista e explica que "o capitalista é o dono dos meios de produção - edifícios, máquinas, matéria-prima etc.; compra a força de trabalho. É da associação dessas duas coisas que decorre a produção capitalista" (HUBERMAN, 1979, p. 168).

Ao aprofundar suas análises sobre o funcionamento do sistema capitalista Catani (1988) reuniu as contribuições de dois entre os principais teóricos: Weber e Marx. Weber explica que o capitalismo é constituído pelo legado da reforma protestante na Europa, ocorrendo uma extrema valorização do trabalho e a prática de uma profissão. 
Mas, para Marx o capitalismo é um modo de produção de mercadorias desenvolvido historicamente desde o inicio da idade moderna até o desenvolvimento industrial inglês.

Desde seu inicio o desenvolvimento do sistema capitalista é impulsionado pela troca, como explica Catani (1988). Ela se divide em duas partes: a transformação da mercadoria em dinheiro (venda) e do dinheiro em mercadoria (compra). Sendo assim o dinheiro é um intermediário da troca de mercadorias, servindo como meio de circulação. A circulação simples de mercadoria (M-D-M) é um processo completo em si, pois através dele um produtor troca sua mercadoria por dinheiro que já não tem valor de uso para ele e com esse dinheiro compra mercadorias que satisfaçam suas necessidades, mercadorias que para ele terão valor de uso. Enquanto o fim da circulação M-D-M é satisfazer uma necessidade de determinada qualidade e quantidade limitada, o princípio e o fim da circulação D-M-D é o dinheiro, mas a soma de dinheiro tem que ser maior no fim do processo, e consequentemente o processo de expansão do capital não conhece limites.

Essa lógica capitalista se expande almejando a acumulação do capital pelo desenvolvimento de dois grandes processos interdependentes como demonstrou Arrighi (2009): a criação de um sistema de Estados nacionais e a formação de um sistema capitalista mundial. As análises de Arrighi (2009) pretendem compreender as mudanças na configuração espacial dos processos de acumulação do capital demonstrando que o capitalismo e os Estado Nacionais cresceram juntos. As hegemonias do capitalismo histórico se desenvolveram a partir do século XV na Itália centrado em Veneza, Florença, Gênova e Milão, em que "o sistema mundial moderno se formou e se expandiu com base em recorrentes reestruturações fundamentais, lideradas e governadas por sucessivos Estados hegemônicos" (ARRIGHI, 2009, p. 30-31).

A riqueza e o poder da oligarquia capitalista deram a Holanda a possibilidade de ocupar o lugar da hegemonia capitalista italiana em que "as redes comerciais e financeiras que a oligarquia capitalista holandesa havia tecido a partir dos impérios ultramarinos e coloniais" (ARRIGHI, 2009, p. 30-31), perfazendo assim o segundo ciclo sistêmico de acumulação do capital. Fica, portanto, demonstrado que "pequenos territórios podiam transformar-se em imensos continentes de poder, buscando acumular apenas riqueza, em vez de adquirir mais territórios e súditos" (p. 39).

O terceiro ciclo sistêmico de acumulação capitalista fez de Londres o novo 
centro dirigente das finanças mundiais no início da década de 1780 , principalmente pela expansão fenomenal da indústria britânica. A expansão da indústria siderúrgica britânica teria que buscar "novos usos para os produtos baratos que seus novos grandes fornos eram capazes de produzir", salienta Arrighi (2009, p. 164). As construções das ferrovias geraram demandas entre as organizações governamentais e empresariais do mundo inteiro. "Entre 1845-49 e 1870-75, as exportações britânicas de ferro e aço para ferrovias mais do que triplicaram, enquanto as de maquinaria aumentaram nove vezes" (ARRIGHI, 2009, p. 165).

Arrighi (2009) prossegue com a análise dos processos mundiais de acumulação de capital tendo como periodização aproximada e preliminar a duração de mais de um século. O ciclo norte-americano tem inicio no fim do século XIX. Como quarto ciclo sistêmico ele se estende até a fase atual tendo como principal característica a expansão financeira. "A capacidade norte-americana de administrar o sistema monetário mundial continuava nitidamente inferior à capacidade residual da própria Grã-Bretanha" (ARRIGHI, 2009, p. 280), Todavia, explica Arrighi, que

No fim da Segunda Guerra Mundial, já estavam estabelecidos os principais contornos desse novo sistema monetário mundial: em Bretton Woods foram estabelecidas as bases do novo sistema monetário mundial; em Hiroshima e Nagasaki, novos meios de violência haviam demonstrado quais seriam os alicerces militares da nova ordem; em San Francisco, novas normas e regras para a legitimação da gestão do Estado e da guerra tinham sido explicitadas na Carta das Nações Unidas (ARRIGHI, 2009, p. 283).

Essas unidades básicas para a análise dos processos mundiais de acumulação de capital contribuíram para que Arrighi coloque em questão a liderança mundial norte-americana. Entretanto, a América do Norte e a Europa Ocidental ainda ditam as ordens no alto comando da economia mundial. Até quando isso persistirá ninguém sabe.

\section{A teoria científica e a análise do pesquisador}

Com esses importantes referenciais de análise o olhar de quem pesquisa ganha novas perspectivas. As características do bairro Ana Jacinta, um dos bairros mais populosos de Presidente Prudente (SP) foi construído como abrigo da classe trabalhadora cuja ocupação do terreno por parte da construtora foi realizada sem nenhuma preocupação com a existência de mananciais ou nascentes. Nenhuma preocupação com a mata nativa 
que protegesse estes; nem com a fauna e a flora existentes naquela área, que fossem importantes para preservação ambiental.

Era um bairro periférico à cidade, com uma distância mínima de 12 quilômetros do centro da cidade, não possuía asfalto, nem uma área de comercio e somente uma ou duas linhas de ônibus circulava por aquela região. Como se tornam ilustrativas as análises de Huberman (1979) segundo o qual,

Com o advento da máquina a vapor, já não era necessário às fábricas se localizarem junto às quedas-d'água como antes. A indústria mudou-se para áreas de minas de carvão, e quase que da noite para o dia lugares sem importância se tornaram cidades, e antigas vilas passaram a cidades (HUBERMAN, 1979, p. 192).

Guardada as devidas proporções as considerações de Huberman (1979) corroboram com a percepção da instalação desse bairro. Naquele tempo como hoje, o avanço da tecnologia possibilitou a implantação das fábricas e das moradias das pessoas em lugares distantes da água, pois a energia que movimentava a indústria não vinha mais da água, vinha do carvão que alimentava as máquinas a vapor; e que a água e energia necessárias para a manutenção das residências domésticas poderiam ser canalizadas e transmitidas.

Fazendo uma ligação com o bairro Ana Jacinta, algumas indústrias e principalmente as moradias começaram a ocupar as áreas periféricas de Presidente Prudente, e uma dessas áreas periféricas é o bairro Ana Jacinta, onde se instalaram as fábricas e as residências domésticas para classe média e baixa, e o setor de comércio e serviços continuava se localizando no centro da cidade. As pessoas que ocuparam este local eram os trabalhadores destas indústrias e do comércio existente na cidade. Novamente as considerações de Huberman (1979) ampliaram e continuam ampliando a compreensão, pois "a Revolução Industrial trouxe consigo a concentração dos trabalhadores nas cidades, a melhoria dos transportes e comunicações, essencial a uma organização nacional" (HUBERMAN,1979,p.202).

Isto explica o desenvolvimento do comércio do Ana Jacinta, na ocupação inicial deste bairro, não existiam muitas opções, mas com o aumento da concentração das pessoas nessa área, os empresários viram que aquele bairro tinha potencial para 0 desenvolvimento do comércio, pelo seu tamanho, ou seja, pela população numerosa e 
também pela distância do bairro até centro, sendo mais prático para os indivíduos consumirem ali por perto.

\section{Considerações finais}

Para ampliar a compreensão da questão ambiental é imprescindivel estabelecer diálogos com diversos pesquisadores para conhecer suas análises por meio das quais refletir a abrangência da questão ambiental e da sua possivel dependência com o modelo de desenvolvimento capitalista. São discussões que auxiliam conhecer de que modo os modelos de desenvolvimento e de que forma o sistema capitalista foi se expandindo no globo impondo, diretamente ou não, sua hegemonia. Trata-se, na verdade de conhecer suas concepções verificando a atualidade delas e debatendo as perspectivas advindas do avanço e do aperfeiçoamento tecnológico.

Com as concepções retiradas das leituras bibliográficas, das discussões e das reflexões de suas análises a visão do pesquisador descobre perspectivas confirmando na prática o que foi tratada na teoria. Assim as informações obtidas pela observação "in loco" da realidade do bairro em análise ampliaram-se as compreensões de que pode ser possível de que a questão ambiental é um dos resultados do modelo de desenvolvimento econômico.

\section{Referências bibliográficas}

ARRIGHI, Giovanni. O longo século XX Dinheiro, Poder e AS Origens de Nosso Tempo 7ํㅡㄹ impressão. Rio de Janeiro: Contraponto, 2009.

CATANI, Afrânio Mendes. O que é capitalismo. 26aㅗ ed. São Paulo: Brasiliense, 1988.

DIAMOND, Jared., Colapso Como as sociedades escolhem o fracasso ou o sucesso 8aㅡ edição. Rio de Janeiro: Record, 2012.

HUBERMAN, Leo., Historia da Riqueza do Homem 15ª edição. Rio de Janeiro: Zahar Editores, 1979

LEFF, Enrique. Complexidade, Interdisciplinaridade e Saber Ambiental. In: Interdiciplinaridade em Ciências Ambientais, PHILIPPI JUNIOR, Arlindo, TUCCI, C.E.M., HOGAN, D.J., NAVEGANTES, Raul (editores), São Paulo: Signus, 2000, p. 19-51. 
MAZOYER, M. \& ROUDART, L. História das agriculturas do mundo: do neolítico à crise contemporânea. Lisboa: Ed. Histórias e Monografias, 1998.

SEN, Amartya. Desenvolvimento como liberdade. $7^{a}$ impr. São Paulo: Companhia das Letras, 2008.

SÓGLIO, Fábio Kessler Dal. O Desenvolvimento Rural no Brasil e na América Latina: como estão nossos projetos. In: Desenvolvimento Rural no Cone Sul. Desarrollo Rural en el Cono Sur, ALMEIDA, Jalcione e MACHADO, J.A.D. (orgs.) Porto Alegre: Associação Holos Meio Ambiente e Desenvolvimento (e-book), 2009, p. 311-336. 